University of Nebraska - Lincoln

DigitalCommons@University of Nebraska - Lincoln

USDA National Wildlife Research Center - Staff Publications
U.S. Department of Agriculture: Animal and Plant Health Inspection Service

July 2002

\title{
Use of sensory cues by fish crows Corvus ossifragus preying on artificial bird nests
}

Leonard Santisteban

Kathryn E. Sieving

University of Florida

Michael L. Avery

USDA National Wildlife Research Center, michael.I.avery@aphis.usda.gov

Follow this and additional works at: https://digitalcommons.unl.edu/icwdm_usdanwrc

Part of the Environmental Sciences Commons

Santisteban, Leonard; Sieving, Kathryn E.; and Avery, Michael L., "Use of sensory cues by fish crows Corvus ossifragus preying on artificial bird nests" (2002). USDA National Wildlife Research Center - Staff Publications. 461.

https://digitalcommons.unl.edu/icwdm_usdanwrc/461

This Article is brought to you for free and open access by the U.S. Department of Agriculture: Animal and Plant Health Inspection Service at DigitalCommons@University of Nebraska - Lincoln. It has been accepted for inclusion in USDA National Wildlife Research Center - Staff Publications by an authorized administrator of DigitalCommons@University of Nebraska - Lincoln. 


\title{
Use of sensory cues by fish crows Corvus ossifragus preying on artificial bird nests
}

\author{
Leonard Santisteban, Kathryn E. Sieving and Michael L. Avery
}

Santisteban, L., Sieving, K. E. and Avery, M. L. 2002. Use of sensory cues by fish crows Corvus ossifragus preying on artificial bird nests. - J. Avian Biol. 33: 245-252.

\begin{abstract}
How predators locate avian nests is poorly understood and has been subjected to little experimental inquiry. We examined which sensory stimuli were important in the nest-finding behavior of fish crows Corvus ossifragus, a common nest predator in the southeastern United States. Using an array of potted trees in a large enclosure, we presented artificial nests to captive crows and quantified responses to visual, auditory, and olfactory nest cues, and nest position. Partial ranks of nest-treatment preferences were analyzed using log-linear models. Nest visibility significantly increased the likelihood of predation by fish crows and increasing nest height was a marginally significant influence on nest vulnerability; no responses were apparent to auditory or olfactory stimuli. Our findings demonstrate that fish crows are visually-oriented nest predators that may preferentially prey on, or more readily encounter, above-ground nests. Moreover, the experimental design provides a new method for evaluating predator-prey interactions between nests and their predators. This study also illustrates how sensory capabilities of predators can interact with nest types to determine nest predation patterns.
\end{abstract}

L. Santisteban (correspondence) and K. E. Sieving, Department of Wildlife Ecology and Conservation, University of Florida, P. O. Box 110430, Gainesville, FL 32611-0430, USA.E-mail: coereba@hotmail.com.M. L.Avery, USDA National Wildlife Research Center, Florida Field Station, 2820 E. University Avenue, Gainesville, FL 32641, USA.

Assessing the influence of nest predation pressure on avian community dynamics relies principally on approaches that quantify nest predation rates on natural and artificial nests. Differences in nest predation patterns are then used to explain observed variation in behavioral, ecological, and life history traits (e.g., Martin 1995). Considerable attention has been paid to identifying nest design features that deter predation (Jones and Hungerford 1972, Martin and Roper 1988, Clark and Nudds 1991, Filliater et al. 1994), and speculation abounds regarding how nest characteristics interact with the sensory capabilities of predators. For example, mammalian predators are presumed to rely on olfactory stimuli (Clark and Wobeser 1997), while avian predators are thought to be visually-oriented (Dwernychuk and Boag 1972, Harriman and Berger 1986, Sugden and Beyersbergen 1986). However, a distinct lack of direct (causal) evidence links the behavioral and sensory capabilities of nest predators to selection pressures in avian communities (cf. Malcolm 1992).

(C) JOURNAL OF AVIAN BIOLOGY

JOURNAL OF AVIAN BIOLOGY 33:3 (2002)
Ultimately, understanding nest predator foraging behaviors and tactics, which are defined, in part, by species' sensory capabilities, is integral to interpreting the diversity and operation of prey defenses (Collias and Collias 1984, Picman 1988, Malcolm 1992). Interpreting prey responses to predation pressure, in this context, requires the identification of the prevailing nest predator sensory modes within a community and the determination of the role of sensory modes in defining selection pressures on avian nest defense.

Using an experimental approach, we examined how different sensory stimuli associated with natural nests were used by an avian nest predator, the fish crow Corvus ossifragus, to find artificial nests. Visual, auditory, and olfactory cues, and nest position treatments were presented to captive crows with a factorial design. We hypothesized that the nest predator would exhibit the strongest responses to nest cues appropriate to its prevailing sensory mode(s). Therefore, we predicted that fish crows would preferentially prey on highly 
visible nests (Dwernychuk and Boag 1972, Sugden and Beyersbergen 1986), although our experimental design accommodated the possibility that they may rely on multiple sensory cues. Results from the experimental trials suggest that nest visibility significantly increased the likelihood of predation by fish crows. Increasing nest height was a marginally significant influence on nest predation, while there were no apparent responses to auditory and olfactory stimuli. This study is the first to experimentally assess the use of multiple sensory cues by an avian nest predator preying on artificial bird nests. It also demonstrates an effective methodology that can be used to identify the sensory capabilities of other vertebrate nest predators.

\section{Methods}

\section{Study species}

The corvid family (Corvidae) includes numerous nest predators (e.g., New and Old World crows and jays; Bent 1946, Sugden and Beyersbergen 1986, Yahner and Cypher 1987, Ehrlich et al. 1988, Johnson et al. 1989, Reitsma et al. 1990, Andrén 1992). Fish crows are widespread in the southeastern coastal plain of the United States and are proficient nest predators (Goodwin 1986, Shields and Parnell 1986). We captured fish crows in north-central Florida, USA, during June-August 1997 using two Australian (drop-in) crow traps $(2 \times 3 \times 3 \mathrm{~m}$; Schemnitz 1980) baited with bread, dry dog food, and raw chicken parts. Each bird was fitted with a uniquely numbered metal leg band. Crows could not be confidently sexed based on external morphology (Pyle et al. 1987). Because of potential differences in nest predation experience between adults and young, individuals were aged and classified as either hatch-year or adult (after hatch-year), following Pyle et al. (1987). Only adult crows were used for these experiments. Crows were paired and housed in $1.8 \times 1.2 \times 1.2 \mathrm{~m}$ cages in an open-air, roofed aviary at the United States Department of Agriculture, National Wildlife Research Center, Florida Field Station (hereafter referred to as FFS), Gainesville, Florida, USA. Crows received a daily maintenance diet of dry dog food and fresh fruits and vegetables (based on United States Department of Agriculture Standard Operating Procedure for fish crows). All individuals tested (below) were fed ad libitum for several days before trials.

\section{Nest presentations}

We conducted experimental trials in an outdoor aviary located at FFS. The $46 \times 46 \mathrm{~m}(0.22 \mathrm{ha})$ test aviary is enclosed by $2.5 \mathrm{~cm}$ hexagonal mesh wire poultry netting, with a peaked roof rising from $3 \mathrm{~m}$ high on two sides to a peak of $7.6 \mathrm{~m}$ (Daneke and Avery 1989). The aviary contains a variety of natural vegetation at the south end, including a southern magnolia Magnolia grandiflora tree that reaches the top of the roof, a dense cluster of saw palmetto Serenoa repens (approx. $9 \mathrm{~m}^{2}$ ), and approximately 20 cultivated blueberry Vaccinium sp. bushes.

Artificial nests were presented within a circular array of vegetation (radius $6 \mathrm{~m}$ ) established in the northern half of the aviary. The array consisted of eight clusters of dense vegetation, each with four potted trees placed directly adjacent to each other; clusters were spaced approximately $3 \mathrm{~m}$ apart (Fig. 1). Only native tree species were used: winged elm Ulmus alata, shumard oak Quercus shumardii, southern magnolia, holly Ilex opaca, live oak Quercus virginiana, river birch Betula nigra, and bluebeech Carpinus caroliniana. Even though we attempted to represent each species among vegetation clusters equally, clusters varied in species composition, foliage density, width (approx. $1.5 \mathrm{~m}$ ), and height (approx. $2 \mathrm{~m}$ ), resulting in vegetative heterogeneity. Located at the center of the vegetation array was a 1.5 $\mathrm{m}$ high perch.

Artificial nests were constructed from wicker canary nests $(10 \times 6 \mathrm{~cm}$; Ethical Products, Inc. $)$ lined inside
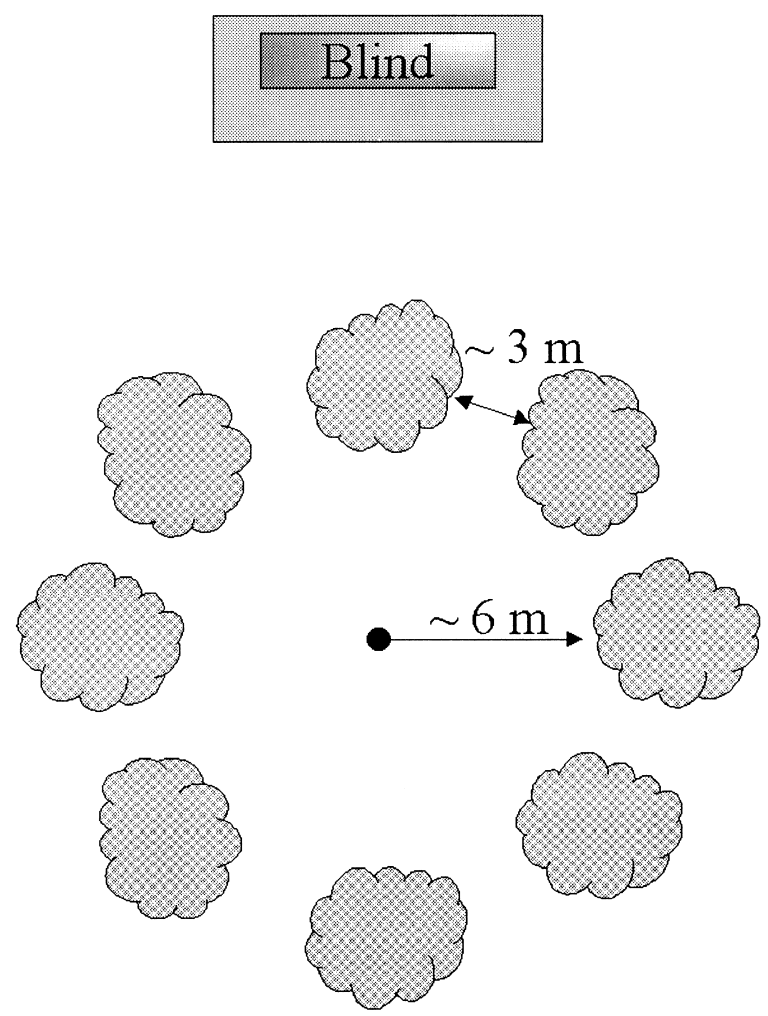

Fig. 1. Schematic diagram of the observation blind and vegetation array in which artificial nests were located. The spot in the center of the circular array of vegetation clusters denotes a $1.5 \mathrm{~m}$ perch. Figure not drawn to scale. 
and out with spanish moss Tillandsia usneoides, small twigs, and fine grasses (inside only) to resemble the medium-sized nest of many passerine species common to the region (Harrison 1975, Ehrlich et al. 1988). Natural-looking nests reduce the biases associated with the spurious appearance of artificial nests that have been used in some experiments (see review by Major and Kendal 1996). We baited nests with one Japanese quail Coturnix japonica egg (G. Q. F. Manufacturing Co., Savannah, GA). Egg dimensions for this species were taken from the literature $(31.0 \pm 0.7 \times 24.0 \pm 0.2$ $\mathrm{mm}$; Montevecchi 1976). The purported biases associated with the use of these eggs in artificial nest studies (Roper 1992, Haskell 1995, Rangen et al. 2000, but see Craig 1998) are unimportant in these trials due to the relatively large gape size of fish crows, and our observations that they could handle and consume the eggs during pre-trial feedings. Artificial nests and eggs were handled with rubber gloves to reduce human scents.

\section{Experimental design}

Eight fish crows were presented with multiple artificial nests, each containing a unique combination of visual, auditory, and olfactory stimuli and a nest position effect (height above the ground) in a four-factor $\left(2^{4}\right)$ factorial design. In this way, we could test for the relative importance of, and interactions among, different sensory stimuli and the effect of nest position on the species' foraging behavior (Box et al. 1978). Each stimulus existed in two states. Nest visibility represented the visual stimulus. Nest visibility categories were selected to represent both extremes of the nest visibility continuum. Nests were either $\geq 75 \%$ visible (visible nest) or $\leq 25 \%$ visible (concealed nest). We determined nest visibility by estimating the mean percentage of each nest visible from $1 \mathrm{~m}$ directly above and below (shrub nests only) the nest, at each of the four cardinal directions on a plane at the height of the nest, 45 degrees above (shrub nests only), and 45 degrees below that plane (Holway 1991).

To test for a position effect, we placed nests either approximately $1.5 \mathrm{~m}$ above the ground in vegetation clusters (shrub nests) or on the ground (ground nests). Height of nest placement was limited by nest substrate height. Actual height of shrub nests varied slightly because of variability in the degree of nest concealment within each vegetation cluster, due in part to seasonal vegetative growth. We placed ground nests in a shallow depression in the soil at the base of the trees; concealment was provided by naturally-growing herbaceous ground cover.

Auditory and olfactory stimuli were either present or absent. The auditory stimulus, nestling begging calls, was presented with a concealed cassette player placed adjacent (within $10-30 \mathrm{~cm}$ ) to all nests. For ground nests, players were concealed within herbaceous ground cover adjacent to nests. For shrub nests, players were tied to or wedged between branches and concealed among vegetation. Cassette players had a built-in speaker (Optimus ${ }^{\text {TM }}$ CTR-105, Radio Shack, USA) and a $60 \mathrm{~s}$ continuous-loop cassette emitting nestling begging calls recorded from three northern mockingbird Mimus polyglottos nestlings, or players were turned off, depending on the treatment. Recordings were made using a cassette recorder (TCM-5000EV, Sony Corp., Japan) and a "shotgun" directional microphone (ME 67, Sennheiser Corp., USA). The frequency at which begging calls were replayed was $3-4$ begging calls every $20 \mathrm{~s}$. We set the amplitude at which begging calls were presented so that they were audible to us from across the shrub array. We assumed that fish crows could also hear the auditory cue if the individual was situated across the array from a nest with the positive auditory cue. The olfactory stimulus consisted of both fresh $(<1$ $\mathrm{d}$ old) avian fecal matter and feathers (from captive boat-tailed grackles Quiscalus major and domestic chickens Gallus gallus, respectively) placed inside nests. Many bird species remove fecal sacs from young nestlings at an early age, but nests are occasionally soiled by older nestlings or adults (e.g., Clark and Wobeser 1997). Feathers are commonly used as lining material in nests and have been suggested to influence predation rates (Møller 1987, Lombardo et al. 1995, Clark and Wobeser 1997).

The $2^{4}$ factorial design resulted in 16 nest treatments, each representing a unique combination of the four factors (see Appendix). Only 8 treatments were presented simultaneously due to spatial constraints in the aviary, therefore, we presented two blocks of 8 nest treatments (Box et al. 1978). Each crow was exposed to the two experimental trials on consecutive days, and exposed to all 16 nest treatments only once (each crow was a replicate).

\section{Trial protocol}

For acclimation, individual crows were moved into the test aviary $48 \mathrm{~h}$ prior to a trial. Food and water were provided at the center of the shrub array to increase the likelihood that test subjects would begin foraging there when trials began. Maintenance diet was provided during the first $24 \mathrm{~h}$ of the acclimation period but was removed on the second day to sharpen the individual's appetite. During the $48 \mathrm{~h}$ acclimation period, two artificial nests, each containing one Coturnix egg, were presented to test subjects to pique their interest in egg consumption. We placed the nests conspicuously at the center of the array; one on the ground and the other approximately $0.5 \mathrm{~m}$ above the ground on a table where food was provided. 
The block of nest treatments presented on a given day of a trial, and each of the 8 nest treatments presented on a given day were randomly assigned to vegetation clusters; each vegetation cluster contained one nest. Nests were placed in vegetation at dusk the evening preceding a trial (cf. Sonerud and Fjeld 1987). At this time, a crow was usually perched greater than $20 \mathrm{~m}$ away from the experimental array in the southern end of the aviary. We are unsure whether or not each crow was able to observe our activities during experimental set-up; however, the crow never approached or inspected nests after trial set-up (LS pers. obs.). Olfactory and auditory stimuli were applied to nests prior to sunrise the morning of the experiments, after which the observer entered the observation blind. LS observed all trials from the blind at the north end of the aviary (Fig. 1).

Trials, lasting four hours, began either when vegetation arrays were visible to the observer from the observation blind or when crows were first observed moving about the aviary. A digital stopwatch was used to record latency to each predation event. At the end of the trial period, all nests were recovered from the aviary. The second block of nest treatments was presented to the test subject the following day. After exposure to both treatment blocks (i.e., all 16 nest treatments) individuals were released from the aviary.

\section{Statistical analysis}

The 16 nest treatments presented to crows were considered independent food items. Because no crow preyed on (i.e., selected) all 16 nest treatments, trials produced a series of partially-ranked data (Harrison 1997). Nest treatment preferences, based on partial ranks, were determined by compiling Mann-Whitney preference counts for each pairwise comparison of nest treatments in all experimental trials. Preference counts are based on the proportion of times, for example, that nest treatment A was preferred over nest treatment B. Preference counts for all trials were then arranged into a $16 \times 16$ matrix with empty cells along the diagonal. We then fit a main-effects Bradley-Terry log-linear model to the preference matrix (Harrison 1997). Goodness of fit for the model and estimates for the model coefficients were provided by PROC GENMOD (SAS Institute, USA). Additionally, a main-effects general log-linear model was used to independently assess the influence of each of the four factors on the first and second nests selected by the crows.

\section{Results}

Of 120 nests presented to the 8 adult fish crows, 45 $(38 \%)$ were preyed upon. The number of nests preyed

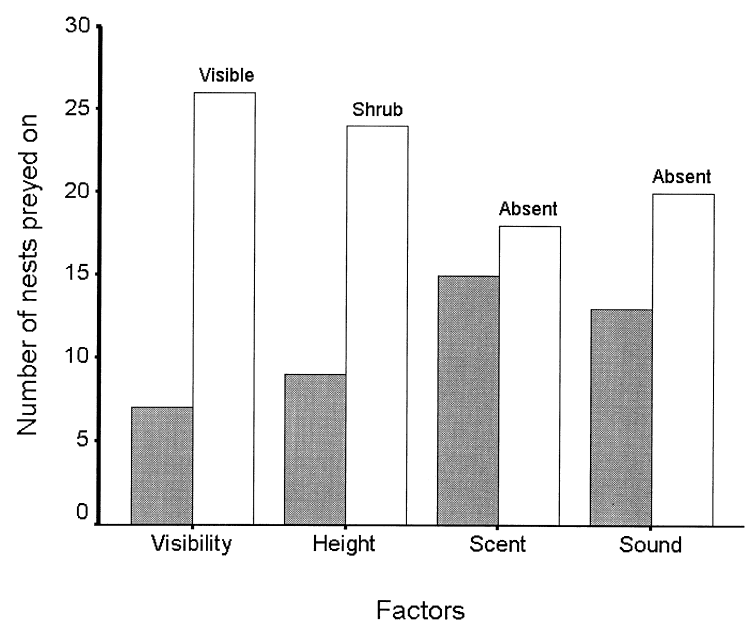

Fig. 2. Number of artificial nests preyed on within each state of the four factors presented to fish crows. Fish crows preyed on significantly more visible nests than concealed nests.

on by each crow varied from 1 to 12 (mean $\pm \mathrm{sd}$; $5.6 \pm 3.4, \mathrm{n}=8$; median $=5.0$ ). The number of nests preyed upon by a crow on the first day $(2.6 \pm 2.3$, $\mathrm{n}=8$; median $=2.5$ ) of a trial did not differ from the number preyed upon on the second day $(3.0 \pm 1.4$, $\mathrm{n}=8$; median $=3.0$; Wilcoxon's signed-ranks test: $\mathrm{P}(2-$ tailed) $>0.05)$. The second block of nest treatments presented to one of the 8 fish crows was eliminated from subsequent analyses because of researcher error. Further analyses of treatments presented on the second day of trials will thus have a sample size of 7 .

Because goodness-of-fit tests suggest no significant lack of fit of the main-effects model (i.e., without interactions terms; Deviance $=22.53, \mathrm{df}=100, \mathrm{P}>$ $0.5)$, interactions among the four factors are suggested to be unimportant. The coefficient estimates of the Bradley-Terry model for each nest treatment resulted in preference rankings based on (i) the number of times a particular nest treatment was preyed on and (ii) the order in which it was selected (i.e., nests chosen first received a higher preference count than nests chosen second). The seven nest treatments with the highest preference rankings were all visible nests, and all nests selected first or second were visible. The influence of the other three factors was less obvious (Fig. 2). Analysis of the first nest selected in each trial indicated that visibility was the only factor determining whether a nest was preyed on first $($ Deviance $=3.77, \mathrm{df}=11, \mathrm{P}<0.05$ ). Similarly, analysis of the nests chosen second showed that visibility was the primary factor determining whether a nest was preyed on second (Deviance $=6.16$, $\mathrm{df}=11, \mathrm{P}<0.05)$, although the shrub condition was also marginally important $(\mathrm{P}=0.10)$, as more shrub nests were selected than ground nests. There were no significant differences in predation patterns between nest treatments with and without the olfactory and auditory stimuli (Fig. 2). 
Latencies to predation of the first nest on each of the first and second day of trials were not significantly different from each other (Mann-Whitney U-test: $\mathrm{U}=$ $12, \mathrm{~N}_{1}=6, \mathrm{~N}_{2}=8, \mathrm{P}(2$-tailed $\left.)>0.10\right)$. Similarly, there were no significant differences in latency to predation of second and third nests by crows from one day to the next (second nest preyed on: $\mathrm{U}=10, \mathrm{~N}_{1}=5, \mathrm{~N}_{2}=7$, $\mathrm{P}(2$-tailed $)>0.10$; third nest preyed on: $\mathrm{U}=9, \mathrm{~N}_{1}=4$, $\mathrm{N}_{2}=6, \mathrm{P}(2$-tailed $\left.)>0.5\right)$. Fig. 3 shows the latency to predation for the first, second, and third nests preyed on during the first and second day of trials. Sample sizes vary because fish crows did not always prey on a second or third nest within a trial.

\section{Discussion}

We provide experimental evidence that the predatory behavior of fish crows in an aviary was principally influenced by the visibility of artificial nests. Our results are consistent with opportunistic observations and inferences derived from field studies, which suggest that visibility is a frequent correlate of nest discovery by corvids in communities where they are known to be active nest predators (Harriman and Berger 1986, Sugden and Beyersbergen 1986, 1987, Yahner and Cypher 1987, Major 1990, Rangen et al. 1999). For example, Sugden and Beyersbergen (1987) demonstrated that American crows Corvus brachyrhynchos were less likely to prey on concealed ( $<20 \%$ visible) simulated duck nests than more visible nests, and that nest survival increased with cover height and density. Generalized

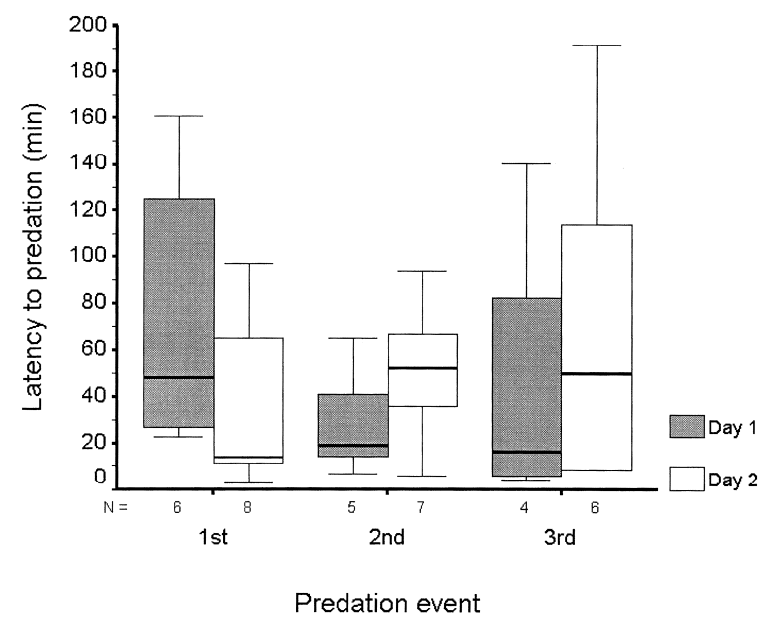

Fig. 3. Latency to predation of first, second, and third nest treatments by fish crows did not differ between the first and second trials. The box represents the interquartile range which contains $50 \%$ of the values. The whiskers are lines that extend from the box to the highest and lowest values, excluding outliers. The line across the box indicates the median. The sample sizes for first, second, and third nests preyed on are shown below the abcissa.

JOURNAL OF AVIAN BIOLOGY 33:3 (2002) assessments of the importance of nest visibility for nest success in field studies lacking predator identification or measures of predator activity produce mixed (Götmark et al. 1995), negative (Holway 1991, Filliater et al. 1994), or positive results (e.g., Jones and Hungerford 1972, Sugden and Beyersbergen 1987, Martin and Roper 1988) that are difficult to interpret with respect to causal factors. Most nest predator communities are diverse; consequently, nests are exposed to a variety of predator sensory and search capabilities. Nest detection by visually-oriented predators is therefore likely to be confounded by competing pressures imposed by predators using alternative foraging strategies (Reitsma et al. 1990, Filliater et al. 1994). For this reason, studies of nest success lacking information about the relative importance of particular predator species, and their associated foraging behaviors, often generate ambiguity regarding links between nest visibility and predation (e.g., Holway 1991, Filliater et al. 1994, Götmark et al. 1995).

Fish crows in our trials preyed slightly more often on shrub than ground nests. This non-significant difference could stem from the small sample size. Similar patterns in nest predation as a function of nest height have been observed in some field studies where corvids are known nest predators (Møller 1987, Filliater et al. 1994, Hannon and Cotterill 1998). However, corvids are not restricted to preying on above-ground nests. Yahner and Cypher (1987) found that blue jays Cyanocitta cristata 'disturbed' similar numbers of low $(0.5 \mathrm{~m})$ and high $(1.5 \mathrm{~m})$ artificial nests. Similarly, Sieving and Willson (1999) photographed equal numbers of Steller's jays $C$. stelleri at ground nests and shrub nests. The overall influence of nest position on the likelihood of discovery by corvids may reflect an interaction between habitat structure and species-specific foraging behavior. In a landscape where corvid abundance increases with the proportion of forest fragmented by agriculture, incidents of predation on ground nests (in forests) by jackdaws $C$. monedula, black-billed magpies Pica pica, and hooded crows $C$. corone increase with forest fragmentation (Andrén 1992). In that same study, European jays Garrulus glandarius and ravens $C$. corax preyed on more nests in more heavily forested areas than in agriculture-dominated landscapes. Moreover, corvids are influential nest predators in open wetland and prairie habitat, where nests occur primarily on the ground (Dwernychuk and Boag 1972, Johnson et al. 1989, Clark and Nudds 1991). Given the behavioral complexity of corvids, it would be foolish to over-generalize about their habitat use patterns, but we conclude that where understory vegetation is sufficiently complex, corvid predation may be biased toward nests above the ground (this study, Rangen et al. 1999), but in all habitats may be distributed throughout vertical strata wherever nests occur (Møller 1987, 1989, Sloan et al. 1998). Increased sample sizes could potentially lead 
to a significant difference in nest predation patterns as suggested by the studies above.

Regarding auditory cues in nest-finding, nest predators are known to respond to nestling begging calls (Haskell 1994, 1999, Briskie et al. 1999), but fish crows in our study did not appear to use them as a cue. The crows may not have heard the stimulus we presented, as it has been suggested that the begging call frequencies of some ground-nesting birds approach the upper limit of the hearing abilities of some avian nest predators (Dooling 1982, Haskell 1999). A cursory analysis of the frequency range of the begging calls used in these trials, however, shows that the most intense frequency (6080 $\mathrm{Hz}$ ) is below the high-frequency cut-off recorded by Dooling (1982) for American crows $(7000 \mathrm{~Hz})$ (L. Santisteban unpubl. data). Moreover, the recordings used were from northern mockingbirds - a species that builds its nests above-ground, possibly allowing for the development of begging calls that are more audible than some ground-nesting bird species. Fish crows may have recognized the begging calls of the northern mockingbird, an antagonistic species that defends its nests aggressively, causing them to avoid risking an encounter with a defensive adult. It is more likely that crows do not normally rely on aural cues at close range because of the large scale at which they operate and their omnivorous diet. Rice (1982) argued that the use of aural cues by avian predators requires substantial morphological, physiological, and behavioral specializations, as exhibited by owls and harriers, which hunt for living prey using sound.

Olfaction has traditionally been considered a poorly developed sensory modality in birds, and we obtained no evidence that fish crows used scents to locate nests in an aviary setting. Some corvids, however, do exhibit functional olfactory abilities (Waldvogel 1989). Harriman and Berger (1986) showed that in the apparent absence of visual cues, ravens were able to locate odoriferous food items in choice tests. While inference in that study is limited by the use of the same 8 ravens throughout 348 experimental trials, it is possible that ravens would have sensory capabilities similar to other wide-ranging birds that rely principally on scavenging (e.g., cathartid vultures; Waldvogel 1989). While most corvids rely on scavenging to some extent, it is unlikely that scent is a reliable cue for nest-finding, given our findings. While the efficient nest sanitation behavior of most passerines birds (e.g., fecal sac removal; Collias and Collias 1984) may be an adaptation to reduce predation pressure from nest predators relying on scent cues, it is not a likely response to predation pressure by fish crows, or perhaps corvids in general. The use of feathers as nest lining may be possible in communities where the most influential predators are not primarily olfactory-oriented.

This experimental design, while novel in its approach, presents potential complications. The potential correla- tion between nest height and nest visibility (i.e., nest visibility may, in part, be determined by nest position) may complicate the use of both of these factors in the design (Burhans and Thompson 1998). If nest position had not been included as a factor in the design, it would have been possible to present the 8 resulting nest treatments in one day, thereby simplifying the experiments. While nest position may be a correlate of nest visibility, it also likely influences the foraging behavior of avian nest predators (Rangen et al. 1999); consequently, we were interested in testing the significance of nest position to the predatory behavior of fish crows. The use of two levels for each factor in the factorial design results in the possibility that both visibility treatments lie above or below a critical threshold for response. However, we feel that this artifact of the design is not relevant to fish crows. To our knowledge, there is no documented threshold for visibility of nests that has been documented in fish crows. Further research into the significance of varying degrees of nest visibility to fish crow predation would shed light on the potential effects of a critical response threshold. Nest visibility may have also been confounded by the heterogeneity in vegetation composition and density (Burhans and Thompson 1998). However, quantifying nest visibility for each nest treatment and randomizing the placement of nest treatments within and among trials would likely control such effects.

The use of each individual on two consecutive days of trials may have contributed to learning by each crow. Yet, results from this study suggest that this is unlikely. Fig. 3 shows that latency to predation (an indicator of learning) on first, second, or third nests was not significantly different between the first and second day of trials, contrary to what one would otherwise expect. If fish crows were learning to prey on the nests in these trials one would expect that latency to predation would decrease on the second day of trials relative to the first day. While latency to predation seems to not be influenced by learning, it may reflect the behavioral state of an animal. For example, fish crows may have delayed foraging for second or third eggs because they were sated, yet there were no clear patterns in latency to predation among first, second, and third nests.

Acknowledgements - We are particularly grateful to D. Levey for insightful comments while developing the experimental design and G. Jones for integral assistance with statistical analyses. We are also grateful to the personnel of the United States Department of Agriculture, National Wildlife Research Center, Florida Field Station, particularly K. Roca, for invaluable assistance in all aspects of wildlife care and handling as well as for use of facilities throughout the experiments. Assistance in construction of the array was provided by E. Tillman and D. Decker. P. Frederick kindly provided us with the use of the night vision scope. We also would like to express our gratitude to members of the "Bird Brains" discussion group at the University of Florida, M. Eckman, G. Jones, D. Levey, J. Morrison, M. Willson, J. Picman and two anonymous review- 
ers for their comments on earlier versions of the manuscript. This project was carried out under the provisions of animal care and use permit (\# A-118) from the Institutional Anima Care and Use Committee at the University of Florida. Partial funding for this study was provided by the University of Florida, Department of Wildlife Ecology and Conservation to KES. This study was also supported by a University of Florida Graduate Assistantship, Jennings Scholarship Fund, and Marjorie McNeil Scholarship Fund to LS. This research was supported by the Florida Agricultural Experiment Station, and approved for publication as Journal Series No. R-08941.

\section{References}

Andrén, H. 1992. Corvid density and nest predation in relation to forest fragmentation: a landscape perspective. - Ecology 73: $794-804$.

Bent, A. C. 1946. Life histories of North American jays, crows, and titmice, Order Passeriformes. - U.S. Government Printing Office, Washington.

Box, G. E. P., Hunter, W. G. and Hunter, J. S. 1978. Statistics for experimenters: an introduction to design, data analysis, and model building. - John Wiley \& Sons, Inc., New York.

Briskie, J. V., Martin, P. R. and Martin, T. E. 1999. Nest predation and the evolution of nestling begging calls. Proc. R. Soc. Lond. B. 266: 2153-2160.

Burhans, D. E. and Thompson, F. R. I. 1998. Effects of time and nest-site characteristics on concealment of songbird nests. - Condor 100: 663-672.

Clark, R. G. and Nudds, T. D. 1991. Habitat patch size and duck nesting success: the crucial experiments have not been performed. - Wildl. Soc. Bull. 19: 534-543.

Clark, R. G. and Wobeser, B. K. 1997. Making sense of scents: effects of odour on survival of simulated duck nests. - J. Avian Biol. 28: 31-37.

Collias, N. E. and Collias, E. C. 1984. Nest building and bird behavior. - Princeton University Press, Princeton.

Craig, D. P. 1998. Chipmunks use leverage to eat oversized eggs: support for the use of quail eggs in artificial nest studies. - Auk 115: 486-489.

Daneke, D. E. and Avery, M. L. 1989. Effective plot size for testing red-winged blackbird repellents in a large flight pen. - In: Fagerstone, K. A. and Curnow, R. D. (eds). Vertebrate pest control and management materials. Vol. 6 ASTM STP 1055. Am. Soc. Test. Materials. Philadelphia, pp. $19-27$.

Dooling, R. J. 1982. Auditory perception in birds. - In: Kroodsma, D. E. and Miller, E. H. (eds). Acoustic communication in birds, Vol. 1. Acad. Press, Inc., New York, pp. $95-130$

Dwernychuk, L. W. and Boag, D. A. 1972. How vegetative cover protects duck nests from egg-eating birds. - J. Wildl. Manage. 36: 955-958.

Ehrlich, P. R., Dobkin, D. S. and Wheye, D. 1988. The birder's handbook: a field guide to the natural history of North American birds. - Simon \& Schuster, Inc., New York.

Filliater, T. S., Breitwisch, R. and Nealen, P. M. 1994. Predation on northern cardinal nests: does choice of nest site matter? - Condor 96: 761-768.

Goodwin, D. 1986. Crows of the world, 2nd ed. - St. Edmunds Press, Ltd., London.

Götmark, F., Blomqvist, D., Johansson, O. C. and Bergkvist, J. 1995. Nest site selection: a trade-off between concealment and view of the surroundings? - J. Avian Biol. 26: 305-312.

Hannon, S. J. and Cotterill, S. E. 1998. Nest predation in aspen woodlots in an agricultural area in Alberta: the enemy from within. - Auk 115: 16-25.
Harriman, A. E. and Berger, R. H. 1986. Olfactory acuity in the common raven (Corvus corax). - Physiol. Behav. 36: $257-262$.

Harrison, H. H. 1975. A field guide to the bird's nests (United States east of the Mississippi River). - Houghton Mifflin Co., New York.

Harrison, J. M. 1997. Evaluation of manatee feeding preferences from partial ranks. - Proc. 5th Annu. Conf. Southeast SAS Users Group, Jacksonville, FL, pp. 377379.

Haskell, D. G. 1994. Experimental evidence that nestling begging behaviour incurs a cost due to nest predation. Proc. R. Soc. Lond. B. 257: 161-164

Haskell, D. G. 1995. Forest fragmentation and nest predation: Are experiments with Japanese quail eggs misleading? Auk 112: 767-770.

Haskell, D. G. 1999. The effect of predation on begging-call evolution in nestling wood warblers. - Anim. Behav. 57: 893-901.

Holway, D. A. 1991. Nest-site selection and the importance of nest concealment in the black-throated blue warbler. Condor 93: 575-581.

Johnson, D. H., Sargeant, A. B. and Greenwood, R. J. 1989. Importance of individual species of predators on nesting success of ducks in the Canadian Prairie Pothole Region. Can. J. Zool. 67: 291-297.

Jones, R. E. and Hungerford, K. E. 1972. Evaluation of nesting cover as protection from magpie predation. - J. Wildl. Manage. 36: 727-732.

Lombardo, M. P., Bosman, R. M., Faro, C. A., Houtteman, S. G. and Kluisza, T. S. 1995. Effect of feathers as nest insulation on incubation behavior and reproductive performance of tree swallows (Tachycineta bicolor). - Auk 112: 973-981.

Major, R. E. 1990. The effect of human observers on the intensity of nest predation. - Ibis 132: 608-611.

Major, R. E. and Kendal, C. E. 1996. The contribution of artificial nest experiments to understanding avian reproductive success: a review of methods and conclusions. Ibis 138: 298-307.

Malcolm, S. B. 1992. Prey defence and predator foraging. In: Crawley, M. J. (ed.). Natural enemies: the population biology of predators, parasites, and diseases. Blackwell Scientific Publications, Cambridge, pp. 458-475.

Martin, T. E. 1995. Avian life history evolution in relation to nest sites, nest predation, and food. - Ecol. Monogr. 65: $101-127$.

Martin, T. E. and Roper, J. J. 1988. Nest predation and nest-site selection of a western population of the hermit thrush. - Condor 90: 51-57.

Møller, A. P. 1987. Egg predation as a selective factor for nest design: an experiment. - Oikos 50: 91-94.

Møller, A. P. 1989. Nest site selection across field-woodland ecotones: The effect of nest predation. - Oikos 56: 240246.

Montevecchi, W. A. 1976. Egg size and the egg predatory behaviour of crows. - Behav. 57: 304-320.

Picman, J. 1988. Experimental study of predation on eggs of ground-nesting birds: effects of habitat and nest distribution. - Condor 90: 124-131.

Pyle, P., Howell, S. N. G., Yunick, R. P. and DeSante, D. F. 1987. Identification guide to North American passerines. Slate Creek Press, Bolinas.

Rangen, S. A., Clark, R. G. and Hobson, K. A. 1999. Influence of nest-site vegetation and predator community on the success of artificial songbird nests. - Can. J. Zool. 77: $1676-1681$

Rangen, S. A., Clark, R. G. and Hobson, K. A. 2000. Visual and olfactory attributes of artificial nests. - Auk 117: $136-146$.

Reitsma, L. R., Holmes, R. T. and Sherry, T. W. 1990. Effects of removal of red squirrels, Tamiasciurus hudsonicus, and 
eastern chipmunks, Tamias striatus, on nest predation in a northern hardwood forest: an artificial experiment. Oikos 57: 375-380.

Rice, W. R. 1982. Acoustical location of prey by the marsh hawk: adaptation to concealed prey. - Auk 99: 403-413.

Roper, J. J. 1992. Nest predation experiments with quail eggs: too much to swallow? - Oikos 65: 528-530.

Schemnitz, S. D. 1980. Wildlife management techniques manual, 4th ed. - Wildlife Society, Washington.

Shields, M. A. and Parnell, J. F. 1986. Fish crow predation on eggs of the white ibis at Battery Island, North Carolina. Auk 103: 531-539.

Sieving, K. E. and Willson, M. F. 1999. A temporal shift in Steller's jay predation on bird eggs. - Can. J. Zool. 77: 18291834 .

Sloan, S. S., Holmes, R. T. and Sherry, T. W. 1998. Depredation rates and predators at artificial bird nests in an unfragmented northern hardwood forest. - J. Wildl. Manage. 62: 529-539.
Sonerud, G. A. and Fjeld, P. E. 1987. Long-term memory in egg predators: an experiment with a hooded crow. - Ornis Scand. 18: $323-325$.

Sugden, L. G. and Beyersbergen, G. W. 1986. Effect of density and concealment on American crow predation of simulated duck nests. - J. Wildl. Manage. 50: 9-14.

Sugden, L. G. and Beyersbergen, G. W. 1987. Effect of nesting cover density on American crow predation of simulated duck nests. - J. Wildl. Manage. 51: 481-485.

Waldvogel, J. A. 1989. Olfactory orientation by birds. - In: Power, D. M. (ed.). Curr. Ornithol, Vol. 6. Plenum Press, New York, pp. 269-321.

Yahner, R. H. and Cypher, B. L. 1987. Effects of nest location on depredation of artificial arboreal nests. - J. Wildl. Manage. 51: 178-181.

(Received 26 February 2001, revised 11 December 2001, accepted 31 December 2001.)

Appendix. Nest treatments presented to fish crows, number of times they were preyed on, Bradley-Terry log-linear model parameter estimates, and combinations of the four factors constituting nest treatments. Treatments are presented in order of preference rankings ( 1 being most preferred). The state of each factor is denoted by a ' 0 ' or ' 1 '. For Visibility, ' 0 ' = visible nest, ' 1 ' $=$ concealed nest (see text). For Height, ' 0 ' = above-ground (shrub) nest, ' 1 ' = ground nest. As for Olfactory and Auditory stimuli, ' 0 ' $=$ absence of the stimulus, whereas ' 1 ' $=$ presence of the stimulus.

\begin{tabular}{|c|c|c|c|c|c|c|c|}
\hline Rank & Treatment no. & Visibility & Height & Olfactory & Auditory & Times chosen & Parameter estimate \\
\hline 1 & 1 & 0 & 0 & 0 & 0 & 5 & 96.93 \\
\hline 2 & 5 & 0 & 0 & 1 & 0 & 5 & 96.91 \\
\hline 3 & 9 & 0 & 0 & 0 & 1 & 4 & 96.45 \\
\hline 4 & 13 & 0 & 0 & 1 & 1 & 4 & 96.34 \\
\hline 5 & 11 & 0 & 1 & 0 & 1 & 3 & 96.17 \\
\hline 6 & 3 & 0 & 1 & 0 & 0 & 2 & 95.65 \\
\hline 7 & 7 & 0 & 1 & 1 & 0 & 3 & 95.64 \\
\hline 8 & 10 & 1 & 0 & 0 & 1 & 2 & 95.45 \\
\hline 9 & 6 & 1 & 0 & 1 & 0 & 2 & 95.40 \\
\hline 10 & 2 & 1 & 0 & 0 & 0 & 2 & 95.25 \\
\hline 11 & 8 & 1 & 1 & 1 & 0 & 1 & 94.73 \\
\hline 12 & 12 & 1 & 1 & 0 & 1 & 0 & 70.42 \\
\hline 13 & 4 & 1 & 1 & 0 & 0 & 0 & 68.62 \\
\hline 14 & 14 & 1 & 0 & 1 & 1 & 0 & 47.18 \\
\hline 15 & 15 & 0 & 1 & 1 & 1 & 0 & 23.85 \\
\hline 16 & 16 & 1 & 1 & 1 & 1 & 0 & 0.0 \\
\hline
\end{tabular}

